\title{
Understanding the Theoretical Perspectives of the Adolescence Education Programme (AEP) in India
}

\author{
$\underline{\text { Kiirii Aniljoy', Virendra B Shahare }}^{2}$ \\ ${ }^{1}$ Research Scholar, Department of Social Work, Jamia Millia Islamia, New Delhi, India. \\ ${ }^{2}$ Associate Professor, Department of Social Work, Jamia Millia Islamia, New Delhi, India. \\ DOI: https://doi.org/10.24321/2349.2880.201913
}

\section{I $\quad \mathbf{N} \quad \mathbf{F} \quad \mathbf{O}$}

\section{Corresponding Author:}

Kiirii Aniljoy, Department of Social Work, Jamia Millia Islamia, New Delhi, India.

\section{E-mail Id:}

kiirii.aniljoy@gmail.com

Orcid Id:

https://orcid.org/0000-0001-9144-3525

How to cite this article:

Aniljoy K, Shahare VB. Understanding the Theoretical Perspectives of the Adolescence Education Programme (AEP) in India. Ind J Youth Adol Health 2019; 6(3): 20-27.

Date of Submission: 2020-01-20

Date of Acceptance: 2020-02-19

\section{$\begin{array}{llllllll}\mathbf{A} & \mathbf{B} & \mathbf{S} & \mathbf{T} & \mathbf{R} & \mathbf{A} & \mathbf{C} & \mathbf{T}\end{array}$}

There is little research focusing on Adolescence Education Programme (AEP) in India. This paper focuses on developing an understanding about the historical and theoretical perspectives of AEP in India based on the extensive review of literature carried out on the subject. The paper explains the AEP and explores the historical and theoretical perspectives of AEP in India. It also attempts to understand how AEP had its beginning in India by discussing the global as well as national developments responsible for the conceptualization and subsequent implementation of AEP in India. The paper concludes that the introduction of AEP can be linked to concerns for Sex Education and Population Education Programmes initiated in response to demographic changes witnessed in different regions of the world. The paper recommends for sustaining and improving the AEP since it has a great potential to make positive impact among adolescents.

Keywords: Adolescents, Adolescence Education Programme, Theoretical Perspectives

\section{Introduction}

Adolescence Education Programme (AEP) is as an educational response to the need for support, encouragement, clarifications and information that adolescents often express in order to make sense of their rapidly changing world. ${ }^{1}$ The programme was launched by the Ministry of Human Resource and Development (MHRD), Government of India in 2005 in all the States and Union Territories in collaboration with National AIDS Control Organisation (NACO). It is addressed primarily to the students of secondary and higher secondary stages (class IX-XII) and aims to provide young people with accurate, age appropriate and culturally relevant information; promote healthy attitudes and develop skills to enable them to respond to real-life situations effectively. ${ }^{2}$ AEP focuses on three major components; namely, Process of growing up from childhood to adulthood, HIV/ AIDS and Drug (substance) abuse.

The term 'Adolescence Education' was used for the first time when the UNESCO Principal Regional Office for Asia and the Pacific (PROAP) published a package on sex and sexuality containing four modules: physical aspect, social aspect, sex roles and sexually transmitted diseases. It named the package as Adolescence Education. However, the concept of Adolescence Education was operationalized in India only when National Council of Educational Research and Training (NCERT) organised a national seminar on Adolescence Education in April 1993 with the main objective 
to evolve a consensus on the issue of the introduction of sex education in the school curriculum. This is the reason why many people in India felt that the term 'Adolescence Education' was being used as a euphemism of sex education with a view to enhancing the acceptability of this sensitive education area. ${ }^{3}$ But the concept of Adolescence Education is broader than that of sex education as it incorporates all the critical concerns of the period of adolescence such as process of growing up from childhood to adulthood, HIV/ AIDS and drug (substance) abuse.

AEP is implemented by different agencies at various levels. At the national level, the programme is coordinated by NCERT and implemented in partnership with the MHRD and United Nations Population Fund (UNFPA). The implementing agencies include Council of Board of School Education (COBSE), Central Board of Secondary Education (CBSE), National Institute of Open Schooling (NIOS), Kendriya Vidyalaya Sangathan (KVS) and Navodaya Vidyalaya Samiti (NVS).

AEP works through both co-curricular and curricular formats. The interventions for curricular approach include support for integration of life skills and adolescent concerns in the learning materials of NIOS at the secondary level. The co-curricular approach works through the three national systems: CBSE, KVS and NVS. The program works on a cascade training approach that has created a pool of master trainers who orient nodal teachers who are entrusted with the responsibility of transacting life skills based education (16 hours module) to secondary school students through interactive methodologies. Nodal teachers are provided guidelines and materials to facilitate the transaction process. Advocacy sessions are organized with principals of participating schools and sensitization sessions are held with parents. By end of 2010, at least two nodal teachers from 3500 CBSE schools, all the 919 KV schools, and all the 583 NVS schools have received orientation on adolescence education issues. ${ }^{4}$

\section{Historical and Theoretical Perspectives of AEP}

The word 'adolescence' is derived from the Latin verb 'adolescere' which literally means to grow into maturity. The concept of adolescence has its roots in the early writings of Plato and Aristotle. These classical writers saw adolescence period as a time of changeability and vulnerability that required careful character education and social restraint.

Plato ( $4^{\text {th }}$ century B.C.) opined that reasoning first appears in adolescence and, therefore, thought that they should study science and maths. He further wrote that males under the age of 18 should not be permitted to drink because 'fire must not be poured on fire'.

Aristotle ( $4^{\text {th }}$ century B.C.) saw adolescence as a period that involves the capacity to make life choices and to develop self control. According to him, adolescents were more disposed to sexual desire and exercised no self-restraint. Brussell, ${ }^{5}$ also expressed adolescence as the period when the young feel that their parents should be told the facts of life.

In the middle age, adolescents were viewed as miniature adults and often subjected to rigid discipline. However, in the early agricultural communities age-wise segregation was atypical and adolescents interacted with young and adults alike taking on the roles of workers and parents (adults) rather unobtrusively.

French Philosopher J.J. Rousseau in the $18^{\text {th }}$ century first gave an enlightened view of adolescence-the view that development has distinct phases. Rousseau like Plato considered reasoning as the important characteristic of adolescence and focused on the development of curiosity in the education of 12 to 15 years old. Ages between 15 to 20 years were considered important for emotional maturity and development of a concern for others.

Adolescence as a period distinct from childhood and adulthood can be attributed to a consequence of two events: compulsory education in America and industrialization. ${ }^{6}$ The late nineteenth and early twentieth century witnessed a deep interest in this stage of life among psychologists, educationists and reformers, who began developing behaviour norm for adolescents. Early writings portray adolescence as a period of potential difficulty. This period saw a lot of literature published related to child rearing advice and moral problems related to the youth. The writing in this period led to the emergence of the concept of youth as a critical transition period in the life of nearly everyone.

G. Stanley Hall (1844-1924), ${ }^{7}$ described as the father of the scientific study of adolescence gave the first public expression to the formal concept of adolescence. Profoundly influenced by the evolutionary theory of Charles Darwin he viewed that the children dominated by instincts and beyond the bound of environmental influences are in the animal stage of development. According to Hall ${ }^{7}$ adolescence (1223 years), offers truly enormous possibilities of growth, and is carried for a time beyond the point of the present stage of civilization.

The physiological explanation of Hall, ${ }^{7}$ that views growth in terms of set stages of any kind was considered inadequate and unreasonable by a considerable number of psychologists on the ground of insufficient evidence. Their argument was supported by Margaret Mead's (1901-1978), ${ }^{8}$ famous study of Samoan children which concluded that basic nature of adolescents is not biological but socio-cultural. She found little storm and stress associated with adolescents in Samoa, and attributed it to their culture that provided smooth and gradual transmission from childhood to adulthood.

Leta Hollingworth (1886-1939), ${ }^{9}$ in her work 'The Psychology 
of the Adolescent' also dismissed Hall's idea of storm and stress. Instead, she emphasized the continuity of development and gradualness of change during the adolescent period. The period between 1890 and 1920 is considered as age of adolescence because a lot of legislations were enacted in the US in the interest of adolescents that ensured access of education opportunities and prohibition of employment and work to them.

Subsequent period saw the development of various theories of human development. According to Cobb, ${ }^{10}$ the sources of development have traditionally divided theories into two major models: the organismic and the environmental. The organismic theories understand the behaviour as the unfolding of genetically programmed processes which produce discontinuous development marked by qualitatively different stages. The stage theorists, such as Freud, Erikson and Piaget believed that development is guided in certain universal directions by biological-maturational forces within the individual. Thus, adolescence is a distinct stage of life during which specific type of development occurs in a relatively predictable fashion.

Environmental theories on the other hand emphasize the importance of external factors rather than the individual's internal processes in an adolescent's development. The early theories failed to acknowledge the interactions that always occur between adolescents and the environment in which they are growing. The belief that development occurs throughout life is central to the life span perspective. According to Paul Baltes (1939-2006), ${ }^{11}$ the life span development expert development is constructed through biological, socio-cultural and individual factors working together. The life span perspective enables us to see continuities in the issues that arise at different points in life.

\section{Biological Theory of Adolescence}

The biological view exemplified by Stanley Hall, ${ }^{7}$ considered biogenetic factors (internal maturational forces) as the primary cause of all behavioural and psychological changes in an adolescent and effects of environment are considered minimal. Hall posited four discrete periods of development corresponding to the four stages of development of our species, viz., infancy/ animal; childhood/anthropoid; youth/ half-barbarian and adult/ civilized. Hall, ${ }^{7}$ believed that all individual's development passes through the same four stages and development occurs in an unchangeable and universal pattern. The situation encompasses a variety of contradictions and 'antithetic impulses'. Some of the impulses paired included: hyperactivity and lassitude; happiness and depression; egotism and self-abasement; selfishness and altruism; gregariousness and shyness; sensitivity and cruelty; radicalism and conservatism. According to Hall, ${ }^{7}$ during this transitional period from primitive to civilised behaviour, all adolescents experience an extended period of upheaval, rebellion and suffering. Governed by nature's physiological control over hormones and physical growth, adolescents experience 'storm and stress' more or less continuously amidst various changes and conflicts.

\section{Psycho-Analytic Theory}

This view pioneered by Sigmund Freud (1856-1939), ${ }^{12}$ emphasized the importance of early childhood experiences and unconscious motivations especially sexual urges and aggressive instincts in influencing behaviour. To Freud, ${ }^{12}$ adolescence represents a period of sexual excitement, anxiety and sometimes personality disturbances, while puberty represents the culmination of a series of changes destined to give infantile sexual life its final, normal form. According to Freud, ${ }^{12}$ puberty triggers a reawakening of sexual urges and adolescents are thrown into a period of intra-psychic crises. The main challenge of adolescents is thus to restore a psychic balance and resolve these conflicts.

According to psycho-analytic view, all humans are born with certain instincts, that is, with a natural tendency to satisfy their biologically determined needs for food, shelter and warmth. The satisfaction of these needs is both essential and a source of pleasure which Freud, ${ }^{12}$ refers to as 'sexual'. According to Freud, ${ }^{12}$ personality is fashioned through various psychosexual stages and proposed that people operate through three states of being: the id, which seeks self gratification, super-ego, which seeks to do what is morally proper, and ego, the rational mediator between the id and the super-ego.

Anna Freud (1895-1982), ${ }^{13}$ daughter of Sigmund Freud, however, perceived adolescence as a period of normative disturbance and argued that defiance and oppositionalism encountered in the teenagers are not only normal but desirable. She identified two important defence mechanisms employed by adolescents; intellectualism and asceticism. Intellectualism involves dealing with emotional problems at an abstract, intellectual plane. Asceticism involves self denial or pleasure avoiding. A person with good ego strength (ego's ability to function despite these duelling forces) is able to effectively manage these pressures while those with too much or little ego strength can become too unyielding or too disruptive. According to Anna Freud, ${ }^{13}$ an important task of the adolescence is thus to bring harmony and resolve the id-ego-superego conflict.

\section{Psycho-Social Development Theory}

Erik Erikson's (1902-1994), ${ }^{14}$ theory of psycho-social development maintains that every individual progresses through eight stages of development throughout the life span. Each stage possesses a unique developmental task and simultaneously confronts an individual with a challenge and crisis he/she must resolve. Successful resolution of the 
conflict leads to development of a positive quality but if the conflict stays unresolved or resolved unsatisfactorily, it damages the ego and builds a negative quality.

According to Erikson, ${ }^{15}$ the main task of adolescence is to form a coherent identity and avoid dangers of role diffusion and identity confusion. A failure to establish identity due to role diffusion may push an individual to indulge in self-destructive activities; drugs and alcohol abuse. A meaningless identity is also acquired by engaging in fads to relieve the anxiety created by role diffusion. To Erikson, ${ }^{15}$ development of suitable sense of identity is important for formulating satisfactory personal and vocational goals.

\section{Psycho-social Theory of Developmental Tasks}

This theory was developed by Robert Havighurst (19001991), ${ }^{16}$ by analysing the tasks that children and adolescents must successfully acquire at different stages of life. The developmental tasks are defined as knowledge, skills, functions and attitudes. Successful completion of these tasks at a particular age leads to adjustment and prepares individuals for subsequent harder tasks. The inability to complete the tasks within the time limit makes later learning of tasks more difficult, creates anxiety and social disapproval. The eight major developmental tasks identified for the adolescence period include: accepting one's physique and using body effectively; achieving new and mature relationships with age-mates of both sexes; achieving a masculine or a feminine social sex role; achieving emotional independence from parents and other adults; preparing for an economic career; preparing for marriage and family life; developing a personal ideology and ethical standards and assuming membership in a larger community.

\section{Cognitive Development Theory}

The central belief of the Jean Piaget's,${ }^{17}$ theory of cognitive development is that our ending need to make sense of our universe and our experiences is the driving force behind our cognitive development. Children and adolescents create mental ideas, which Piaget, ${ }^{17}$ called schemas to make sense of the world. The schemas developed through assimilation and accommodations become more symbolic as children mature and go through the four stages of cognitive development theorised by Piaget. ${ }^{17}$ Adolescence marks the transition from the stage of concrete operations during which logical reasoning is limited to the stage of formal operations, during which an individual can generalise at an abstract level. The adolescents think beyond the present and forms theories about everything delighting in consideration of that which is not. They enter the world of ideas and begin to think of all possibilities. They can separate the real from the possible and can analytically reflect about their own thinking as well. They can also make hypothetical deductions and can deal with contrary to fact abstract premises.

\section{Social Cognitive Learning Theory}

Developed by Albert Bandura, ${ }^{18}$ this theory looks at personality as an interaction among three things: the environment, behaviour and the person's psychological processes. According to Bandura, ${ }^{18}$ most human learning is observational that occurs by observing what others do and imitating what one sees. His research provided evidence that exposure to filmed aggression heightened aggressive reactions in adolescents. Bandura and Walters, ${ }^{19}$ observed that adolescents do not do what adults tell them to do but rather do what they see adults do. Bandura, ${ }^{18}$ positioned that self-efficacy would help determine when children would imitate others apart from who the person is and whether that person's behaviour is rewarded.

\section{Sociological, Historical, Anthropological and Ecological Theories}

Adolescence in the discipline of sociology has been examined with a view to emphasise problems that young people face while making transition into adulthood especially in industrial societies. Allison Davis', ${ }^{20}$ 'Theory of Social Anxiety' refers to the tension and discomfort felt by teenagers which motivates and influences behaviour and views development as continuous process of learning socially acceptable behaviours by means of reinforcement and punishment. Due to new developmental and behavioural tasks and increased awareness and sensitivity, the social anxiety increases with the onset of adolescence thereby increasing striving for socially desirable goals. The tension and distress that young people feel about fitting into a particular social group is viewed as powerful motivator to engage in illegal activities.

Historical perspectives offered by Glen Elder, ${ }^{21}$ and Joseph Kett, ${ }^{6}$ point towards larger social, political and economic forces present in a particular time to account for different adolescent experiences for individuals of different groups of people who came of age at a similar point in historical time. Glen's, ${ }^{21}$ study 'Children of Great Depression' challenged the stage-focused developmental theories by demonstrating with compelling data the profound effect of historical changes on human development, not only in the formative years but throughout the life course. Kett, ${ }^{6}$ in his work, 'Rites of Passage: Adolescence in America; 1790 to the present,' argues that if adolescence is defined as the period after puberty during which a young person is institutionally segregated from the casual contacts with a broad range of adults, then it can scarcely be said to have existed at all until the twentieth century.

The anthropological view of adolescence demonstrates the impact of social structures and cultural mores like rites 
of passage on adolescents' behaviour and attitudes. The works of Ruth Benedict, ${ }^{22}$ M. Mead ${ }^{8,4}$ and Kingsley Davis, ${ }^{23}$ provide the evidence to support the notion that social environment is crucial for development. M. Mead, ${ }^{8}$ in her classic work 'Coming of Age in Samoa' acknowledged the role of culture in defining adolescence, 'stress and storm' during adolescence as not a universal phenomenon. She noted that the Samoan adolescents did not experience the stress associated with US adolescents. Her study provides support to the principle of continuity of cultural conditioning.

Ecological view of adolescence by Uri Brofenbrenner (19172005), ${ }^{24}$ describes contexts within which individuals grow and develop as five overlapping spheres of influence, each of which can affect conditions in another sphere. Brofenbrenner, ${ }^{24}$ model puts child at the centre of what can be visualised as concentric circles of contexts, set in an overarching system of time that affects all the contexts and continually changes them. The five systems of ecological theory are the microsystem (immediate environment of direct interactions with parent, teachers, peers etc.), mesosystem (linkages between the microsystem like family and school), exosystem (settings with no active role like extended family), macrosystem (attitudes and beliefs of the culture) and chronosystem (the time dimension). The influence of the peer group microsystem increases during adolescence while a change in parents' life may impact adolescents' lives or a parent's involvement with school can improve an adolescent's academic performance. Thus, an individual's life is embedded in a series of multi-level contexts and functioning of an individual is a product of interactions between the person and the many facets of the environment that continually emerge and change.

\section{The Beginning of AEP in India Global Context}

In the 1830s, US and England witnessed young men who left for school or a job provided with theological, nutritional and philosophical information aimed to help young control their sexual urges until they could be safely expressed in marriage. The rapid urbanization, high incidence of STDs and associated health risks and moral decline led to the movement for sex education. In 1913, Chicago became the first city to implement sex education for high school students. Similarly, programmes of sex education in England grew out of similar anxieties. However, French visualised it more as an effort to prepare young middle class women for the sexual aspects of marriage and reproduction.

After World War II, with the increase in the incidence of STDs especially syphilis and gonorrhoea particularly among soldiers the focus of the programme shifted to social aspect. The programmes introduced under a variety of names such as family life education or human growth and development courses aimed at positive satisfaction from an ordered family life, covered topics as parenting skills, family finances, etc. and emphasised the importance of self-esteem, responsibility and decision-making. In 1980, with the outbreak of AIDS and HIV epidemic, the sexuality education was irrevocably altered. Mandates were passed for comprehensive AIDS and sexuality education in public schools. However, sex education is not always mandatory in western nations. In England and Wales, the parents can refuse their children to take part in some activities that provide information about sex and reproduction.

In most of the developing countries, sex education is a response to the growing HIV/ AIDs epidemic. The history of adolescence education in its present form can be traced to Population Education Programmes that were initiated in response to demographic changes witnessed in different regions of the world. Though talked much earlier, Population Education began only in the late 1960s. The workshop on Population and Family Education (1970), ${ }^{21}$ sponsored by UNESCO Regional office Bangkok is a landmark in the history of Population Education. After initial resistance, five Asian countries (including India) launched National Population Education Programmes with financial support from United Nations Fund for Population Activities (UNFPA) and technical assistance from UNESCO. ${ }^{25}$ Subsequently, International Conference on Population held in Mexico City, 1984, unfolded new dimensions of population education. The five major themes identified were: family size and welfare, delayed marriage, responsible parenthood, population change and resource development ad population related beliefs and values.

The International Conference on Population and Development (ICPD), ${ }^{22}$ held in Cairo, in 1994 is a key document on the international consensus on Population Education. It highlighted that population is not about counting people but making sure that everybody counts. ${ }^{26}$ The ICPD Programme of Action (PoA) 7.46 declares that: 'all countries should protect and promote the rights of adolescents to reproductive health education, information and care and greatly reduce the number of adolescent pregnancies'. PoA 7.47 reads: 'in collaboration with NGOs, all governments have been urged to meet the special needs of adolescents and to establish appropriate programmes to respond to these needs.

The meaning of Population Education varies from country to country and its conceptualisation is a question of emphasis rooted in cultural and historical differences. The principal goal of this education programmes was initially to promote the linkages between population dynamics and development; however, the concerns over a period of time have varied from lowering the population growth 
rate to improving family health to lowering pregnancy rates among adolescents.

Population Education is often linked with Family Life Education, Family Planning Education, Sex Education and Population Studies. There is no universally accepted definition of Population Education but according to UNESCO, ${ }^{25}$ Population Education is defined as 'An education programme which provides for a study of the population situation in the family, country, nation and the world with the purpose of development in students of rational and responsible attitude and behaviour towards that situation.

\section{Indian Context}

In India, sexuality is a paradoxical issue. Ancient Indian history is known for the proliferation of sexual images and literature. Hindu writings such as Manu, Vatsyayana, Altekar and Vedalankar inform us that sex was not a taboo subject. Texts like Kamasutra celebrate eroticism and human sexuality. Phallic symbols are prevalent in ancient sculptures and temples, most notably in relation to the Hindu tradition. ${ }^{27}$ But much of the twentieth century highlights the conservative attitudes towards sexuality in public sphere. Sex is rarely discussed in society. It has been repressed over a period of time and during the colonial period in collective thinking it came to represent a dirty act, a sin that sullied the individual and was ideologically dichotomized from all things sacred and divine. ${ }^{28}$ Even a curriculum proposed for 'sexual hygiene' in the year 1920 was rejected by the Education Board. ${ }^{29}$

A relative liberalization in attitudes towards sexuality occurred in mid 1980s and 1990s. This liberalization was attributed to rapid globalization and the spread of HIV/ AIDS. Subsequently, greater need for sexual health led to the development of programmes of sex education, campaigns targeting HIV awareness, promotion of condom use, dissemination of information in media and education in schools and the like. The concern for the sexual and reproductive health needs and the beginning of AEP therefore has their roots in the dynamics of population growth.

India is the first country to have taken up the task of introducing Population Education into the school system. The concern with population was reflected in the first UNESCO Population Education Programme: India, Dominican Republic Conference in 1968. In the world's first 'National Seminar on Population Education' held in Bombay in August 1969 specific recommendations were made for the evolution of National Population Education Programme (NPEP). The first NPEP was launched in April 1980 with a focus on family life education covering all states and UTs. Re-conceptualisations of Population Education in $1986-87$ and $1998-96$ as a response to recommendations of the International Conference on Population (1984) and Istanbul Declaration and adoption of ICPD Programme of Action necessitated the development of a Framework of Adolescence Education in 1993. ${ }^{30}$

The NPEP with Adolescence Education as the thrust area was implemented in different schools in 33 states and UTs. It was also implemented in the adult education and university education sectors from 1997-2002. The AIDS pandemic and the growing problems related to sexual behaviour of adolescents, drug, tobacco and alcohol use generated a demand for prevention education. In 1992, Indian National Science Congress recommended introduction of sex education in schools. As a response, the Department of Education (under MHRD) and NACO in collaboration with NCERT, UNESCO and UNICEF developed a 'Learning for Life' module in 1993. In the first ever National Seminar on Adolescence Education organised by NCERT in 1993 the concern with adolescents was reflected. The seminar endorsed the use of the concept of adolescence education, its specific connotation and delineated its broad framework and recommended the introduction of suitable components of adolescence education in the curricula at all stages of schooling. ${ }^{31}$

The period between 1994 and 1996 saw a number of regional seminars organised and attended by various stakeholders in order to validate the Adolescence Education Framework and facilitate the process of integration of Adolescence Education into school curriculum. The revised framework for Adolescence Education was developed in 2003-04 incorporating life skills development as an important dimension and reflecting on the newer concerns emphasized in the new policy.

The AEP in its present form came into existence after an inter-ministerial meeting held on 27 October 2004 in the chamber of the Minister of HRD, attended by MHFW, MLE, MRD, MSJE and MIB. The meeting decided to implement HIV prevention education as a co-curricular programme in all 1.5 lakh secondary schools within the overall framework of age relevant health education programmes. A series of subsequent meetings with key stakeholders, officers from MHRD, NACO and representatives from UNICEF and UNFPA led to the culmination of AEP with MHRD identified as the lead agency for the implementation with financial and technical support from NACO, UNICEF and UNFPA.

\section{Conclusion}

Adolescence as a concept is quite old having its roots in the writing of classical writers such as Plato and Aristotle so also is the idea that adolescents are generally disposed to sexual desire and therefore should be trained to develop self control. Human sexuality and sex education for children and the young are reported to be the topic of various 
private publications in Greek for almost 100 years. But the idea that school and state has the responsibility to teach young people about sex is a modern one. Various theories of adolescence, despite their own drawbacks, have proved to be vital in establishing a deeper understanding of this phase of life. These theories have also immensely contributed to the conceptualization of the AEP in India. The origin of AEP in India can be linked to the concern for sex education. However, this concern for sex education became more profound only after the World War II that saw huge movements of soldiers and increase in incidence of STDs. But the present form of AEP is the outcome of Population Education Programmes that were initiated in response to demographic changes witnessed in different regions of the world. Sadly after AEP was finally launched in 2005, there was a widespread protest in the country from different organisations calling for the withdrawal of the programme. The reasons being that sex education has no place in our society, it will corrupt young innocent children's minds, it will destroy the cultural fabric of country and the like [32]. However, review of 48 studies of comprehensive sex and STD/HIV education programmes in US schools, found strong evidence that such programmes did not increase sexual activity. Rather they reduced sexual activity, or increased rates of condom use or other contraceptives, or both and young people can store up information provided at any time, for a time when they need it later on. ${ }^{33}$ Levine, ${ }^{34}$ also convincingly demonstrated that the harm - unwanted pregnancies, higher rates of STDs - comes from shielding children from sexual information, not exposing them to it. According to Chowkhani, ${ }^{35}$ one of the root anxieties of access to sexuality education is the patriarchal and misogynist notion that women will claim their sexual agency and the patriarchy's prerogative to control female sexuality. Ironically, our country had glorified sex and sexuality in the olden days. It was only during the British period that sex became a 'dirty' thing in the collective mindset of the people. In real sense, the protestors had defended a culture that is not their own. As discussed, the concept of Adolescence Education is broader than that of sex education and, hence, should not be treated entirely as sex education but should be sustained and improved by all stakeholders as it incorporates all the critical concerns of the period of adolescence and has a great potential to make positive impact among adolescents.

\section{Conflict of Interest: None}

\section{References}

1. About Adolescence Education Programme (AEP). Need for Adolescence Education. National Council of Educational Research and Training Website. Available from: http://www.aeparc.org/pages. php?id=aboutlse\&ln=en. Accessed on: Feb 15, 2019.
2. Module-1; Adolescence Education in India. Education. National Council of Educational Research and Training Website. Available from: http://www.ncert. nic.in/programmes/aep/pdfs/MODULE\%201\%20 ADOLESCENCE\%20EDUCATION\%20IN\%20INDIA.pdf. Accessed on: Feb 15, 2019.

3. Joshi K. Sexuality in India: Teenager \& Teacher. New Delhi: Kalpaz Publication. 2004. Available from: https:// www.abebooks.com/Sexuality-India-Teenager-TeacherKavita-Joshi/6299905296/bd.

4. UNFPA \& NCERT. Concurrent Evaluation of the Adolescence Education Programme (2010-11). New Delhi: Sammbodhi Research and Communication Pvt Ltd 2011. Available from: http://aeparc.org/upload/43.pdf.

5. Brussell EE. Dictionary of quotable definitions. Englewood Cliffs, NJ: Prentice Hall 1970.

6. Kett JF. Rites of Passage: Adolescence in America 1970 to the present. New York: Basic Books, 1977.

7. Hall GS. Adolescence: Its psychology and its relation to physiology, anthropology, sociology, sex, crime, religion and education, 2 Vols, New York: D Appleton 1904.

8. Mead M. Coming of age in Samoa: A psychological study of primitive youth for western civilization. New York: William Morrow and Company, 1928. Available from: https://en.wikipedia.org/wiki/Coming_of_Age_ in_Samoa

9. Hollingworth LS. Psychology of the adolescent. New York: Appleton-Century, 1928.

10. Cobb NJ. Adolescence: Continuity, change and diversity, $4^{\text {th }}$ ed. London: Mayfield Publishing Company, 2001. Available from: https://www.scirp. org/(S(i43dyn45teexjx455qlt3d2q))/reference/ ReferencesPapers.aspx?ReferencelD=1504210.

11. Baltes Paul B. Life span development and the brain. UK: Cambridge University Press, 2006.

12. Freud S. A general introduction to psychoanalysis. New York: Permabooks, 1953.

13. Freud A. The ego and the mechanism of the defence. New York: International University Press, 1946.

14. Erikson EH. Childhood and society. New York: WW Norton Company, 1950.

15. Erikson EH. Identity, youth and crisis. New York: WW Norton Company, 1968.

16. Harvighurst R. Developmental tasks and education. New York: David McKay, 1972.

17. Piaget J. The theory of stages in cognitive development. In DR Green (Eds.). Measurement and Piaget, New York: McGraw-Hill, 1971.

18. Bandura A. Social learning theory. Englewood Cliffs, NJ: Prentice Hall, 1971.

19. Bandura A, Walters RH. Adolescent aggression: A study of the influence of child training practices and family relationships. New York: Ronald Press, 1959. 
20. Davis A. Socialization and adolescent personality. Adolescence, Yearbook of the National Society for the Study of Education 1944; 43: Part I.

21. Elder GG Jr. Children of the great depression. Social change in life experiences. Chicago: University of Chicago Press, 1974.

22. Benedict R. Patterns of culture. Boston: Houghton Mifflin, 1934.

23. Davis K. The sociology of parent-youth conflict. American Sociological Review 1941; 5: 523-525.

24. Brofenbrenner U. The ecology of human development: Experiments by nature and design. Cambridge, MA: Harvard University Press, 1979.

25. UNESCO. Population and family education. Report of an Asian Workshop. $7^{\text {th }}$ September $\& 7^{\text {th }}$ October, 1970. Regional office for education in Asia. Bangkok: United Nations Educational, Scientific and Cultural Organisation, 1971.

26. UNFPA. Programme of Action adopted at the International Conference on Population and Development. Cairo, 5-13 Sep. 1994. New York: United Nations Population Fund, 1996.

27. Gatwood E. Lynn. Devi and the Spouse Goddess: Women, sexuality, and marriage in India. New Delhi: Manohar, 1985.

28. Banerji R. Sex power, defining history, shaping societies. UK: Penguin, 2008.

29. Shankar U, Shankar L. Sex Education. New Delhi: Sterling Publishers Pvt. Ltd, 1978.

30. UNFPA. Re-conceptualization of population education. New York: United Nations Population Fund, 1993.

31. Muley DS, Pandey JL, Yadav SB, Sadhu K. (Eds). Report of the national seminar on adolescence education. New Delhi: National Council of Educational Research and Training, 1994.

32. Rajya Sabha Committee on Petitions. Hundred and thirty-fifth Report on petition praying for national debate and evolving consensus on the implementation of the policy for introduction of sex education in the schools and holding back its introduction until then. New Delhi: Rajya Sabha Secretariat, 2009.

33. Kirby D, Laris B, Rolleri L. Sex and HIV Education Programs: Their Impact on Sexual Behaviours of Young People throughout the World. Journal of Adolescent Health 2007; 40: 206-217. Available from: https:// www.sciencedirect.com/science/article/abs/pii/ S1054139X0600601X [PubMed/ Google Scholar].

34. Levine J. No Sex Education: From Chastity to Abstinence. In Michael S. Kimmel \& Rebecca F. Plante (Eds.). Sexualities, Identities, Behaviours and Society. New York: Oxford University Press, 2004: 438-453.

35. Chowkhani K. Sexuality Education: Why we need it. Teacher Plus Website. Available from: http://www. teacherplus.org/cover-story/sexuality-education-whywe-need-it. Published on: February 2013. Accessed on February 15, 2019. 